\title{
The Prevalence of Depression in Pregnant Women with Sleep Disorder
}

\author{
Behboodi Moghadam Zahra ${ }^{1}$ and Rezaei Elham ${ }^{*}$ \\ ${ }^{1}$ Phd in Reproductive Health, Faculty of Nursing and Midwifery, Tehran University of Medical Sciences, Tehran, Iran \\ ${ }^{2}$ MSc in Midwifery, Faculty of Nursing and Midwifery, Urmia University of Medical Sciences, Urmia, Iran
}

*Corresponding author: Rezaei Elham, MSc in Midwifery, Faculty of Nursing and Midwifery, Urmia University of Medical Sciences, Urmia, Iran,Tel:+98 9144633116; E-mail address: rezai520@yahoo.com

Received Date: July 15, 2014, Accepted Date: September 23, 2014, Published Date: September 30, 2014

Copyright: ( ) 2014, Rezaei Elham et al., This is an open-access article distributed under the terms of the Creative Commons Attribution License, which permits unrestricted use, distribution, and reproduction in any medium, provided the original author and source are credited.

\begin{abstract}
Introduction: $79 \%$ of the American and $87.2 \%$ of the iranian pregnant women suffer from sleep disorders, these disorders are the result of physiological, hormonal, physical changes originate from different factors can affect disorders before, during, and after childbirth, involve causing of depression during pregnancy. This study aimed to evaluate the depression of pregnant women with sleep disorders in the second and third trimester.
\end{abstract}

Method: This is a cross-sectional study conducted on 972 pregnant women with sleep disorders referring to four health care centers in Makou affiliated to Urmia University of Medical Sciences during June-Oct 2012. Data collection tools included demographic characteristics, Pittsburgh Standard Sleep Quality, and beck depression standard questionnaires. Sampling was done by convenient sampling, and statistical methods used to analysis.

Results: The mean of sleep quality was $7.78 \pm 3.14$ and depression of pregnant women with poor sleep quality reported 71.7 percent also there were significant association between depression and all component of sleep quality $(\leq 0.05)$.

Conclusion: Given that a large percentage of sleep disorders during pregnancy and parallel to the Depression. Hope this period takes place in addition to usual care, structured psychiatric interview, and diagnostic cause of the disturbance.

Keywords: Depression; Pregnant women; Sleep disorder

\section{Introduction}

Pregnancy is one of the most vulnerable and joyful period of a woman's life [1], due to systematic variations caused by hormonal, emotional, mental, and physical factors can affect sleep patterns, ability to perform tasks of daily living, and quality of life of the pregnant woman [2-4] Changes in sleep patterns during pregnancy may increase from 13 to 80 percent in the first trimester to 66 to 97 percent the third trimester [5], lead to daily dysfunction, maternal fatigue, loss of family welfare, increase accidents, as a result, reduce quality of life, and psychological relaxation is induced insomnia, leads to increased anxiety, fear of child care, and accepting maternal role in the family. In this regard, A review of sleep disorder studies in pregnancy represent an increased risk of preterm birth, low birth weight, challenges of pregnancy and during labor, prolonged labor, delivery tools, cesarean, depression during pregnancy, after delivery and in some cases, caused postpartum blues, negative impact on families, society, and indirectly is resulting in economic burden to society [6,7]. According to studies the poor quality of sleep in the second trimester of pregnancy is directly related to depressive symptoms in late pregnancy [8]. Depression during pregnancy is prevalent, as $70 \%$ of pregnant women have some of symptoms $[9,10]$. In several studies, 30.6 percent, 45.7 percent and 57 percent of women will experience symptoms of depression during pregnancy [11,12]. Overall, the results of different studies in different years, the prevalence of depressive symptoms in pregnancy has shown 8-51 percent $[13,14]$. Depression is one the most common psychiatric disorders and mood disorders, according to the world health organization (WHO) depression is the fourth urgent health problem in the world [10], Also depression after delivery is associated with prenatal depression, The most important risk factor and predictor for depressed mood during post partum was prenatal depression and $50 \%$ of women with depression during pregnancy were depressed after delivery [15], Not only lead to complications in the mother and baby after delivery, It also led to the birth of premature infants during pregnancy, low birth weight, poor health behaviors Include: substance use (cigarettes, alcohol, and drugs) not to go for prenatal care and preeclampsia [16,17], Newborns in women experience restlessness, excessive crying, and sleep disturbance during infancy [18].

In the past was thought that pregnancy prevent and protect against depression, While studies suggest that not only the depression in the third trimester has high prevalence, But sleep disorder is considered a normal part of pregnancy and not care about it, Can affect maternal mental, physical, and result in pregnancy, especially led to mood disorders. as well as, efforts for reducing maternal mortality and morbidity in pregnancy to extend prenatal care and delivery have led to maternal and childhood health outcomes, Due to the limited research in this area, Since the priority giving of health services to the health of pregnant women is one of the Millennium Development Goals, Early detection and follow her depression during pregnancy is important. It felt a need for research in the pregnant women with sleep disorder. Thus, the researchers were decided to study in this field .In the hope of being able to increase the protection of women during 
pregnancy. This could be a step toward the realization of their motto "Healthy mother and healthy child".

\section{Material and Method}

In this study, 972 pregnant women with insomnia or poor sleep quality were recruited who referred to four health city center shuttle for receiving prenatal care from Jun 2012 to the end of Nov 2012. Sampling was done by convenient sampling.

Three questionnaires that were adopted in the present study, were a demographic characteristics questionnaire (individual and birth including: age, education, occupation (job), economic status, parity (gravida), gestational age, body mass index (BMI), Interval from previous pregnancy, and previous delivery, Tendency of mother and husband to this pregnancy, smoking, and satisfaction of fetal sex), pittsburg standard sleep quality questionnaire, and beck depression standard questionnaire. After preparation of the questionnaires and obtaining a written permission from the nursing and midwifery school and ethics committee of Tehran University of Medical Sciences, the qualified pregnant women were selected. Inclusion criteria were Iranian nationality, gestational age 15-40 weeks, no diagnosed physical and mental diseases (meditational and psychological), and ability to read and write, not smoking, no drug abuse or consumption of alcoholic drinks, and taking sleep and hormonal medications. After obtaining an informed written consent, a three-section questionnaire including women's demographic characteristics, Pittsburg Standard Sleep Quality questionnaire, and beck depression standard questionnaire were distributed among the qualified individuals to fill them up in a quiet place or completed at home and as soon as possible be delivered the researcher.

After reviewing the inventory eligible questionnaire, the subjects with scores $\geq 5$ Based on the PSQI were diagnosed as subjects with poor sleep quality and women who had received scores of 10 and above according to beck depression standard questionnaire, were identified as depression during pregnancy, then results were reviewed and analyzed by the descriptive statistics and analytical including frequency tables, independent t-test, ANOVA and pearson by spss version 18 software.

This study excluded the thirty-six persons (reasons: 15 persons due to no desire to continue study, 9 persons preterm labor and 3 persons migration to other cities, 3 persons because of abortion). The participants with the symptom of severe depression (Higher score than 31) referred to the physician. The pittsburgh sleep quality index (PSQI) was a retrospective self-report questionnaire that measured sleeping patterns and sleep disturbances that existed during the previous month. The PSQI yields a global score ranging from 0 to 21 . Pittsburg Standard Sleep Quality questionnaire was finally designed by Buysse et al. in 1989 with a sensitivity of $89-6 \%$, specificity of $86.5 \%$, validity of $88 \%(\mathrm{r}=0.88)$, and reliability of $83 \%$. Its validity and reliability were confirmed by research in other countries and in Iran [26-28].

The Nineteen scores of sleep assess with the pittsburgh sleep quality index in the seven "component" scores: subjective sleep quality, sleep latency, sleep duration, habitual sleep efficiency, sleep disturbances, use of sleeping medication, and daytime dysfunction. The sum of scores for these seven components yields one global score. Individuals with PSQI scores $<5$ were categorized as good sleepers, and those with scores $\geq 5$ were classified as poor sleepers.
It is mentioned with regard to the sixth component of pittsburgh sleep quality too lis devoted to the use of sleep medications contraindicated in pregnancy. In this study, so this dimension of the instrument components was not analyzed and after scoring this component of instruments core was zero.

Depressive symptoms were assessed using the validated and reliable 13-item short form beck depression inventory that correlates highly with the long form [29]. The long form BDI has been validated for use with pregnant women [9]. Beck depression questionnaire that contains 21 questions are multiple, each question is scored from zero to three, the total score of the scale is from zero to 63 and Finally, based on the scores of the depressed person was to 1-10 normal, 11-20 mild depression, 21-30 moderate depression, 31 and above severe depression, Beck depression inventory is a standard questionnaire that the reliability and validity have been verified in several studies in Iran.

The Ethics Committee of Tehran University of Medical Sciences approved the study proposal and corroborated its ethical considerations. All participants were informed about the purposes and the methods of this study. The permission to type record the interviews was obtained from the participants. They were informed that participation in the study was voluntary and they could refuse to participate at any time without having any negative impact on the services delivered to them. Those who agreed to participate in the study provided signed written consent.

\section{Results}

The characteristics and sociodemographic data of the 936 participants are summarized in Tables 1, There were no significant associations between depression and women's age, gravida, gestational age, Interval from previous pregnancy, and previous delivery, Tendency of mother and husband to this pregnancy, smoking, and satisfaction of fetal sex $(\mathrm{P}>0.05$ for all). There were associations, however, between depression and education, job, economical status, BMI, and all Component of sleep quality (Table 2) include: subjective sleep quality $(r=0.257)$, sleep latency or delay in falling asleep $(\mathrm{r}=0.199)$, sleep disturbance $(\mathrm{r}=0.249)$, daily dysfunction $(\mathrm{r}=0.358)$, sleep quality score $(r=0.395)$, and was a significant inverse relationship between sleep duration $(\mathrm{r}=-0.192)$ and habitual sleep efficiency $(r=-0.155)$ with depression in Tables $1 \& 2(P \leq 0.05) 816$ participants $(87.2 \%)$ declared having poor sleep quality and 585 of them (71.7\%) indicated depression score (Table 3). The depression in pregnant women in the second and third trimesters of pregnancy equal 67.3, mild depression 43.3, moderate depression 15.7, severe depression 6.4 percent and Extreme depression 1.9 percent. Depression was $71.1 \%$ in pregnant woman with sleep disorders (mild depression 45.2, moderate depression 16.9, and severe depression 7.4, and Extreme depression 2.2 percent) and without sleep disorders was $37.5 \%$.

\section{Discussion}

According to the National Sleep (2007) 79\% of the pregnant women suffer from sleep disorders, also $87.2 \%$ of Iranian pregnant women. More than 72 percent of pregnant women will experience waking up frequently during the night $[6,30]$. Recent research indicates that depression in the second and third trimesters of pregnancy is associated with sleep quality and all components, Also women's job, education and increasing BMI are associated with reducing depression. 
Citation: Zahra BM, Elham R (2014) The Prevalence of Depression in Pregnant Women with Sleep Disorder. J Psychiatry 17: 1000157. doi: $10.4172 / 2378-5756.1000157$

Page 3 of 6

\begin{tabular}{|c|c|c|c|c|}
\hline \multicolumn{2}{|c|}{ Demographic status } & \multirow{2}{*}{$\begin{array}{l}\text { Prevalence (\%) } \\
168(17.9)\end{array}$} & \multirow{2}{*}{\begin{tabular}{|l|} 
M \pm SD \\
$26.47 \quad \pm$ \\
\end{tabular}} & P value ${ }^{*}$ \\
\hline \multirow{7}{*}{ Age } & $15-20$ & & & \\
\hline & $21-25$ & 291 (31.1) & & \\
\hline & $26-30$ & $225(24)$ & & \\
\hline & $31-35$ & $180(19.2)$ & & \\
\hline & $36-40$ & $57(6.2)$ & & \\
\hline & $41-45$ & $12(1.3)$ & & \\
\hline & $46-50$ & $3(0.3)$ & & \\
\hline \multirow[t]{4}{*}{ Education } & primary & $390(41.6)$ & \multirow{4}{*}{----- } & \multirow[t]{4}{*}{$\leq 0.000$} \\
\hline & $\begin{array}{l}\text { steerag } \\
\mathrm{e}\end{array}$ & $213(22.8)$ & & \\
\hline & diploma & $204(21.8)$ & & \\
\hline & $\begin{array}{l}\text { collegia } \\
\text { te }\end{array}$ & $129(13.8)$ & & \\
\hline \multirow[t]{2}{*}{ Job } & Homy & $867(91)$ & \multirow[t]{2}{*}{$\mid----$} & \multirow[t]{2}{*}{$\leq 0.021$} \\
\hline & $\begin{array}{l}\text { Employ } \\
\text { ed }\end{array}$ & $84(9)$ & & \\
\hline \multirow{3}{*}{ Economical Status } & Good & $147(15.7)$ & \multirow{3}{*}{----} & \multirow{3}{*}{$\leq 0.000$} \\
\hline & $\begin{array}{l}\text { Modera } \\
\text { te }\end{array}$ & $720(76.9)$ & & \\
\hline & Bad & $69(7.4)$ & & \\
\hline \multirow{4}{*}{ Gravida } & One & $357(38.1)$ & \multirow{4}{*}{$\begin{array}{ll}1.96 \\
0.95\end{array}$} & \\
\hline & Two & $336(35.9)$ & & \\
\hline & Three & $159(17)$ & & \\
\hline & Four $=<$ & $84(9)$ & & \\
\hline \multirow{5}{*}{$\begin{array}{l}\text { Gastational } \\
\text { Age(week) }\end{array}$} & $15-20$ & $456(48.7)$ & \multirow{5}{*}{$\begin{array}{ll}26.54 \\
9.67\end{array}$} & \\
\hline & $21-25$ & $54(5.7)$ & & \\
\hline & $26-30$ & $42(4.5)$ & & \\
\hline & $31-35$ & $66(7.1)$ & & \\
\hline & $36-40$ & $318(34)$ & & \\
\hline \multirow{6}{*}{ BMI } & $\begin{array}{l}15-18.4 \\
9\end{array}$ & $36(3.8)$ & \multirow[t]{6}{*}{$\begin{array}{l}26.53 \quad \pm \\
4.51\end{array}$} & \multirow[t]{6}{*}{$\leq 0.001$} \\
\hline & $\begin{array}{l}18.5-24 \\
.99\end{array}$ & $291(31.1)$ & & \\
\hline & $\begin{array}{l}25-29.9 \\
9\end{array}$ & $402(42.9)$ & & \\
\hline & $\begin{array}{l}30-34.9 \\
9\end{array}$ & $171(18.3)$ & & \\
\hline & $\begin{array}{l}35-39.9 \\
9\end{array}$ & $33(3.6)$ & & \\
\hline & $\begin{array}{l}40-44.9 \\
9\end{array}$ & $3(0.3)$ & & \\
\hline
\end{tabular}

\begin{tabular}{|c|c|c|c|c|}
\hline \multirow{5}{*}{$\begin{array}{l}\text { Interval from } \\
\text { previous pregnancy }\end{array}$} & $\begin{array}{l}\text { No } \\
\text { interval }\end{array}$ & $333(35.6)$ & \multirow[t]{5}{*}{$\begin{array}{|ll|}2.06 & \pm \\
1.77 & \end{array}$} & \\
\hline & $\begin{array}{l}\text { One } \\
\text { year }\end{array}$ & $84(9)$ & & \\
\hline & $\begin{array}{l}\text { Two } \\
\text { year }\end{array}$ & $66(7.1)$ & & \\
\hline & $\begin{array}{l}\text { Three } \\
\text { year }\end{array}$ & $93(9.9)$ & & \\
\hline & $\begin{array}{l}\text { Four or } \\
\text { more } \\
\text { year }\end{array}$ & $360(38.5)$ & & \\
\hline \multirow{3}{*}{ Previous delivery } & $\begin{array}{l}\text { No } \\
\text { delivery }\end{array}$ & $363(38.8)$ & \multirow[t]{3}{*}{----- } & \\
\hline & $\mathrm{C} / \mathrm{S}$ & $138(14.7)$ & & \\
\hline & NVD & $435(46.5)$ & & \\
\hline \multirow{2}{*}{$\begin{array}{l}\text { Tendency of } \\
\text { pregnancy (Mother) }\end{array}$} & yes & $810(86.5)$ & \multirow[t]{2}{*}{----- } & \\
\hline & No & $126(13.5)$ & & \\
\hline \multirow{2}{*}{$\begin{array}{l}\text { Tendency } \\
\text { pregnancy } \\
\text { (Husband) }\end{array}$} & yes & $810(86.5)$ & \multirow[t]{2}{*}{$\mid----$} & \\
\hline & No & $126(13.5)$ & & \\
\hline \multirow{2}{*}{ Smoking Mother } & yes & $6(0.6)$ & \multirow[t]{2}{*}{$\mid----$} & \\
\hline & No & $930(99.4)$ & & \\
\hline \multirow{2}{*}{ Smoking Husband } & yes & $333(35.6)$ & \multirow[t]{2}{*}{\begin{tabular}{|c|}
---- \\
-
\end{tabular}} & \\
\hline & No & $603(64.4)$ & & \\
\hline \multirow{2}{*}{$\begin{array}{l}\text { Satisfaction of fetal } \\
\text { sex (Mother) }\end{array}$} & yes & $726(77.6)$ & \multirow[t]{2}{*}{$\mid----$} & \\
\hline & No & $210(22.4)$ & & \\
\hline \multirow{2}{*}{$\begin{array}{l}\text { Satisfaction of fetal } \\
\text { sex } \\
\text { (Husband) }\end{array}$} & yes & $711(76)$ & \multirow[t]{2}{*}{ |---- } & \\
\hline & No & $225(24)$ & & \\
\hline Total & |---- & $936(100)$ & |----- & \\
\hline
\end{tabular}

Table 1: Demographic status of pregnant women and correlation to sleep quality

Tiffany and Associates study in 2007 represents during both the second and third trimesters, the depressed women had more sleep disturbances and higher depression, anxiety and anger scores. They also had higher norepinephrine and cortisol levels. The newborns of the depressed mothers had more sleep disturbances including less time of deep sleep, more time off in determinate (disorganized) sleep, more active, and cried/fussed. Another research by Helen and Associates study in 2008, revealed sleep quality early pregnancy predicted higher levels of depressive symptoms at later stage in pregnancy (after controlling for prior depression levels). The other study by Deborah and colleagues reported in 2010, higher depressed mood scores was independently associated with lower $\mathrm{HR}$ QoL in six of the eight domains, including bodily pain, general health, vitality, social functioning, emotional role, and mental health. Also Ekaterina in 2010 showed, physical symptom sat early-mid second trimester predicted 
Citation: Zahra BM, Elham R (2014) The Prevalence of Depression in Pregnant Women with Sleep Disorder. J Psychiatry 17: 1000157. doi:

depressive symptoms in the last trimester both directly, and via poor sleep quality (prospectively), which mediated the relationship.

\begin{tabular}{|c|c|c|c|c|c|}
\hline \multicolumn{2}{|l|}{ Component of sleep quality } & \multirow{3}{*}{$\frac{\mathbf{N}}{93}$} & \multirow{3}{*}{\begin{tabular}{|l|}
$\%$ \\
9.9
\end{tabular}} & \multirow{3}{*}{$\begin{array}{l}\mathrm{M} \pm \mathrm{SD} \\
-\end{array}$} & \multirow{3}{*}{$\begin{array}{l}\text { P value }^{*} \\
0.01 r=0.257\end{array}$} \\
\hline & & & & & \\
\hline \multirow[t]{4}{*}{ Subjective Sleep Quality (component 1) } & $\begin{array}{l}\text { Very } \\
\text { good }\end{array}$ & & & & \\
\hline & good & 618 & 66 & & \\
\hline & bad & 180 & 19.3 & & \\
\hline & Very bad & 45 & 4.8 & & \\
\hline \multirow[t]{4}{*}{ Sleep latency(component 2) } & 0 & 102 & 10.9 & \multirow[t]{4}{*}{$2.84 \pm 1.66$} & \multirow[t]{4}{*}{$0.03 r=0.199$} \\
\hline & $1-2$ & 312 & 33.3 & & \\
\hline & $3-4$ & 363 & 38.8 & & \\
\hline & $5-6$ & 159 & 17 & & \\
\hline \multirow{4}{*}{ Sleep duration(component 3) } & $>7$ hours & 489 & 52.2 & \multirow[t]{4}{*}{$6.62 \pm 1.54$} & \multirow[t]{4}{*}{$0.01 r=-0.192$} \\
\hline & $\begin{array}{ll}6 & - \\
\text { hours } & 7\end{array}$ & 213 & 22.8 & & \\
\hline & $\begin{array}{ll}5- & 6 \\
\text { hours } & \end{array}$ & 153 & 16.3 & & \\
\hline & $<5$ hours & 81 & 8.7 & & \\
\hline \multirow{4}{*}{ Habitual sleep efficiency(component 4) } & $>85 \%$ & 236 & 25 & \multirow[t]{4}{*}{$74.65 \pm 15.37$} & \multirow[t]{4}{*}{$0.02 r=-0.155$} \\
\hline & $75-84 \%$ & 249 & 26.6 & & \\
\hline & $65-74 \%$ & 258 & 27.6 & & \\
\hline & $<65 \%$ & 195 & 20.8 & & \\
\hline \multirow[t]{4}{*}{ Sleep disturbances(component 5) } & 0 & 9 & 1 & \multirow[t]{4}{*}{$9.33 \pm 3.73$} & \multirow[t]{4}{*}{$0.002 r=0.249$} \\
\hline & $1-9$ & 507 & 54.2 & & \\
\hline & $10-18$ & 414 & 44.2 & & \\
\hline & $19-27$ & 12 & 0.6 & & \\
\hline Use of sleeping medication(component 6) & 0 & \multicolumn{2}{|l|}{$\mid-----$} & 0 & ----- \\
\hline \multirow[t]{4}{*}{ Daytime dysfunction(component 7) } & 0 & 231 & 24.7 & \multirow[t]{4}{*}{$2.35 \pm 1.98$} & \multirow[t]{4}{*}{$0.000 r=0.358$} \\
\hline & $1-2$ & 294 & 31.4 & & \\
\hline & $3-4$ & 264 & 28.2 & & \\
\hline & $5-6$ & 147 & 15.7 & & \\
\hline \multirow{2}{*}{ SLEEP QUALITY } & $0-4$ & 120 & 12.8 & \multirow{2}{*}{$7.78 \pm 3.14$} & \multirow{2}{*}{$0.000 r=0.395$} \\
\hline & $5-21$ & 816 & 87.2 & & \\
\hline Total & ----- & 936 & 100 & ----- & ----- \\
\hline
\end{tabular}

Table 2: Seven component of sleep quality in pregnant women and correlation to depression

The results of studies is consistent of the recent research findings about relationship between depression on the second and third trimester pregnancy with sleep quality, subjective sleep quality, sleep latency or delay in falling asleep, sleep duration, sleep efficiency, sleep disturbances and daily function in this period. 
Page 5 of 6

Modabernia and colleagues study in Iran (2009), reported depression rates by $25 \%$ and there was significantly correlated between level of education, employment and number of pregnancies reported with depression during pregnancy. Omidvar and et al in 2007, showed depression rates 28.8 percent, there was a significant relationship between level of education, employment, spouse's consent, helping husband at home work, family support and education of the spouse with depression during pregnancy. Shahmiri and Momtazi research in 2006, revealed depression rates 32 percent, there was a significant relationship between depression during pregnancy with poor economic situation, first pregnancy (having more than three pregnancies), lack of employment outside the home, poor emotional relationship with a partner.

Results of some recent researches findings in Iran is aligned with the employment of women, increasing BMI and depression are associated with a lower education, But the big difference in the prevalence of depression in the study of Iranian Studies can be the variation of sleep quality according to cultural conditions and appropriate culture conditions predisposing to depression.

So, help to mothers for adaptation during and after pregnancy, Maternal mental health promotion by improving their communication skills and attention to her needs at this time, Identify mothers at risk for depression and sleep disorders, finally, In addition to takes place routine prenatal care programs, counseling programs, special programs for research, diagnosis of sleep disorders, troubleshooting the cause of the disturbance, and prevent to provide maternal and child health, in order to achieve the motto of the healthy mother and healthy child.

Like other studies, this study had some limitations, during the answering questions may there are few mental attributes have little impact to answer questions, which was beyond the control of the researcher Alsoun diagnosed disease, the effect of changes in diet and exercise on sleep pattern could affect the study that were uncontrolled.

\begin{tabular}{|c|c|c|c|c|c|c|c|c|c|c|c|c|c|c|}
\hline \multicolumn{2}{|l|}{$\begin{array}{l}\text { Depression } \\
\text { Sleep }\end{array}$} & \multicolumn{2}{|c|}{ Normal 1- 10} & \multicolumn{2}{|c|}{ Mild 11 - 20} & \multicolumn{2}{|c|}{ Moderate 21 - 30} & \multicolumn{3}{|c|}{ Severe 31 - 40} & \multicolumn{2}{|c|}{$\begin{array}{l}\text { Extreme } 41- \\
63\end{array}$} & \multicolumn{2}{|c|}{ Total } \\
\hline & & N & $\%$ & $\mathrm{~N}$ & $\%$ & $N$ & $\%$ & N & \% & & $N$ & $\%$ & $\mathrm{~N}$ & $\%$ \\
\hline \multirow[t]{4}{*}{ Sleep quality } & $0-4$ & 75 & 62.5 & 36 & 30 & 9 & 7.5 & 0 & c & & 0 & 0 & 120 & 100 \\
\hline & & & & 45 & & & & 37.5 & & & & & & \\
\hline & $5-21$ & 231 & 28.3 & 369 & 45.2 & 138 & 16.9 & 60 & & & 18 & 2.2 & 816 & 100 \\
\hline & & & & 585 & & & & \multicolumn{2}{|c|}{$71.7 \%$} & & & & & \\
\hline \multirow[t]{2}{*}{ Total } & & 306 & 32.7 & 405 & 43.3 & 147 & 15.7 & 60 & 6.4 & 18 & & 1.9 & \multirow[t]{2}{*}{936} & 100 \\
\hline & & & & 630 & & & & 67.3 & & & & & & \\
\hline
\end{tabular}

Table 3: Comparison of sleep quality and depression in pregnant women

Tiffany and Associates study in 2007 represents during both the second and third trimesters, the depressed women had more sleep disturbances and higher depression, anxiety and anger scores. They also had higher norepinephrine and cortisol levels. The newborns of the depressed mothers had more sleep disturbances including less time of deep sleep, more time off in determinate (disorganized) sleep, more active, and cried/fussed. Another research by Helen and Associates study in 2008, revealed sleep quality early pregnancy predicted higher levels of depressive symptoms at later stage in pregnancy (after controlling for prior depression levels). The other study by Deborah and colleagues reported in 2010, higher depressed mood scores was independently associated with lower HR QoL in six of the eight domains, including bodily pain, general health, vitality, social functioning, emotional role, and mental health. Also Ekaterina in 2010 showed, physical symptom sat early-mid second trimester predicted depressive symptoms in the last trimester both directly, and via poor sleep quality (prospectively), which mediated the relationship.

The results of studies is consistent of the recent research findings about relationship between depression on the second and third trimester pregnancy with sleep quality, subjective sleep quality, sleep latency or delay in falling asleep, sleep duration, sleep efficiency, sleep disturbances and daily function in this period.

Modabernia and colleagues study in Iran (2009), reported depression rates by $25 \%$ and there was significantly correlated between level of education, employment and number of pregnancies reported with depression during pregnancy. Omidvar and et al in 2007, showed depression rates 28.8 percent, there was a significant relationship between level of education, employment, spouse's consent, helping husband at home work, family support and education of the spouse with depression during pregnancy. Shahmiri and Momtazi research in 2006, revealed depression rates 32 percent, there was a significant relationship between depression during pregnancy with poor economic situation, first pregnancy (having more than three pregnancies), lack of employment outside the home, poor emotional relationship with a partner.

Results of some recent researches findings in Iran is aligned with the employment of women, increasing BMI and depression are associated with a lower education, But the big difference in the prevalence of depression in the study of Iranian Studies can be the variation of sleep quality according to cultural conditions and appropriate culture conditions predisposing to depression.

So, help to mothers for adaptation during and after pregnancy, Maternal mental health promotion by improving their communication skills and attention to her needs at this time, Identify mothers at risk for depression and sleep disorders, finally, In addition to takes place routine prenatal care programs, counseling programs, special programs for research, diagnosis of sleep disorders, troubleshooting the cause of the disturbance, and prevent to provide maternal and child health, in order to achieve the motto of the healthy mother and healthy child. 
Like other studies, this study had some limitations, during the answering questions may there are few mental attributes have little impact to answer questions, which was beyond the control of the researcher Alsoun diagnosed disease, the effect of changes in diet and exercise on sleep pattern could affect the study that were uncontrolled.

\section{Acknowledgment}

The authors greatly appreciate the Dean of nursing and midwifery school in Tehran and Urmia University of Medical Sciences in Iran as well as the personnel of all health care centers and the participants in this study.

\section{References}

1. Sieber S, Germann N, Barbir A, Ehlert U (2006) Emotional well-being and predictors of birth-anxiety, self-efficacy, and psychosocial adaptation in healthy pregnant women. Acta Obstet Gynecol Scand 85: 1200-1207.

2. Hueston WJ, Kasik-Miller S (1998) Changes in functional health status during normal pregnancy. J Fam Pract 47: 209-212.

3. Mckee MD, Cunningham M, Jankowski KR, Zayas L (2001) Healthrelated functional status in pregnancy: relationship to depression and social support in a multi-ethnic population. Obstet Gynecol 97: 988-993.

4. Lopes EA, Carvalho LB, Seguro PB, Mattar R, Silva AB, et al. (2004) Sleep disorders in pregnancy. Arq Neuropsiquiatr 62: 217-221.

5. Moline M, Broch L, Zak R (2004) Sleep Problems Across the Life Cycle in Women. Curr Treat Options Neurol 6: 319-330.

6. Neau JP, Texier B, Ingrand P (2009) Sleep and vigilance disorders in pregnancy. Eur Neurol 62: 23-29.

7. Lee KA, Gay CL (2004) Sleep in late pregnancy predicts length of labor and type of delivery. Am J Obstet Gynecol 191: 2041-2046.

8. Ekaterina K, Helen Sk, Eleanor HW, Susan JP, Jeannette M (2010). A prospective investigation of the relationships among sleep quality, physical symptoms, and depressive symptoms during pregnancy .Journal of Affective Disorders 123: 317-320.

9. Holcomb WL, Stone LS, Lustman PJ, Gavard JA, Mostello DJ (1996) Screening for depression in pregnancy: characteristics of the Beck Depression Inventory. Obstet Gynecol 88: 1021-1025.

10. Kaplan H, Sadocks B (2009). Comprehensive textbook of psychiatry. Lippincott Williams \& Wilkin 1th ed.

11. Pazande F, Tomianc ZH, Afshar F, Valaei N (2008). Prevalence of depression and its associated factors among pregnant women Teaching hospitals of ShahidBeheshti University of Medical Sciences, Tehran, Kermanshah University of Medical Sciences Journal 21: 66-70.

12. Bandad R, Abedian Z, Hasanabadi H, Esmaeili H (2006). Sleep patterns associated with depression. Kermanshah University of Medical Sciences Journal 2: 28-32.

13. Bennett HA, Einarson A, Taddio A, Koren G, Einarson TR (2004) Prevalence of depression during pregnancy: systematic review. Obstet Gynecol 103: 698-709.

14. Zaconeta AM, Queiroz IF, Amato AA, Motta LD, Casulari LA (2013) Depression with postpartum onset: a prospective cohort study in women undergoing elective cesarean section in Brasilia, Brazil. Rev Bras Ginecol Obstet 35: 130-135.

15. Da Costa D, Larouche J, Dritsa M, Brender W (2000) Psychosocial correlates of prepartum and postpartum depressed mood. J Affect Disord 59: 31-40.

16. Steer RA, Scholl TO, Hediger ML, Fischer RL (1992) Self-reported depression and negative pregnancy outcomes. J Clin Epidemiol 45: 1093-1099.

17. Kitamura T, Sugawara M, Sugawara K, Toda MA, Shima S (1996) Psychosocial study of depression in early pregnancy. Br J Psychiatry 168: 732-738.

18. 18. Tiffany Field, Miguel Diego, Maria Hernandez-Reif, Barbara Figueiredo, Saul Schanberg, Cynthia Kuhn (2007). Sleep disturbances in depressed pregnant women and their newborns. Infant Behavior \& Development 30: 127-133.

19. Kelman BB (1999) The sleep needs of adolescents. J Sch Nurs 15: 14-19.

20. Garbarino S, Mascialino B, De Carli F, La Paglia G, Mantineo G, et al. (2003) [Shift-work seniority increases the severity of sleep disorders. Comparison of different categories of shift-workers]. G Ital Med Lav Ergon 25 Suppl: 227-228.

21. Skouteris H, Germano C, Wertheim EH, Paxton SJ, Milgrom J (2008) Sleep quality and depression during pregnancy: a prospective study. J Sleep Res 17: 217-220.

22. Da Costa D, Dritsa M, Verreault N, Balaa C, Kudzman J, et al. (2010) Sleep problems and depressed mood negatively impact health-related quality of life during pregnancy. Arch Womens Ment Health 13: 249-257.

23. Omidvar SH, KHeirkhah F, Azimi H (2007). Depression in pregnancy and associated factors. Hormozgan University of Medical Sciences 3: 213-219.

24. Shahmiri H, Momtazi S (2006). Prevalence of depression and its relationship with the individual characteristics of pregnant women. Medical Journal of Tabriz University of Medical Sciences 28(2): 83-86.

25. Modabernia J, Shojaeitehrani H. Heidarnezhad S (2009). Prevalence of depression in the third trimester. Guilan University of Medical Sciences 71: 19-25.

26. Buysse DJ, Reynolds CF 3rd, Monk TH, Berman SR, Kupfer DJ (1989) The Pittsburgh Sleep Quality Index: a new instrument for psychiatric practice and research. Psychiatry Res 28: 193-213.

27. Yao KW, Yu S, Cheng SP, Chen IJ (2008) Relationships between personal, depression and social network factors and sleep quality in community-dwelling older adults. J Nurs Res 16: 131-139.

28. Malekzadegan A, Moradkhani M, Ashaeri H, Haghani H (2005). The effects of Relaxation exercise training on the sleep disorders in the third trimester of pregnancy, pregnant women referred to health centers in Zanjan. School of Nursing and Midwifery. Thesis for Master of Midwifery. Iran University of Medical Sciences in Iran.

29. Beck AT, Rial WY, Rickels K (1974) Short form of depression inventory: cross-validation. Psychol Rep 34: 1184-1186.

30. Fereshte J, Elham R, Zahra B, Hamid H (2013). Prevalence of sleep disorders in the pregnant women. Journal of the Iranian Institute for Health Sciences Research (Payesh) 12: 629-635. 